\title{
Reseña bibliográfica: Campagno, M., Gallego, J. y García Mac Gaw, C. G. (Comps.) (2016). Regímenes políticos en el Mediterráneo antiguo. Buenos Aires: Miño y Dávila Editores. 286 pp.
}

Palabras clave: Regímenes Políticos - Mundo Antiguo - Estado - Instituciones

Keywords: Political Regimes - Ancient World - State - Institutions

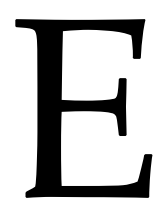

ste libro analiza un conjunto de regímenes políticos muy diversos que se desarrollan en el Mediterráneo antiguo. Está conformado por veinte artículos, presentados originalmente en un coloquio, que buscan enriquecer nuestra apreciación de los procesos que conducen de las situaciones anteriores al surgimiento del Estado a la centralización inherente a dichas estructuras estatales, sin perder de vista el papel de los poderes locales. El desarrollo de estas organizaciones permite reflexionar sobre la política como dimensión fundamental de las prácticas sociales, para lo cual contamos en determinados contextos con las propias observaciones de los antiguos sobre esta esfera de la vida en comunidad.

El nombre de la compilación nos advierte sobre un marco temporal y espacial amplio, que recorre todo el Mediterráneo antiguo. Se encuentra dividido en tres partes, la primera situada en el antiguo Egipto y próximo Oriente, luego, Grecia antigua y, finalmente, el mundo romano y la antigüedad tardía.

"Surgimiento de lo estatal y liderazgo local en el valle del Nilo (IV-III milenios a.C.)" de Marcelo Campagno, abre la primera parte del libro. El autor intenta considerar la evidencia funeraria, iconográfica y textual que provee indicios sobre la existencia de un liderazgo comunal antes y después del advenimiento de lo estatal en el valle del Nilo, con el doble objetivo de conferirle alguna visibilidad al problema y de intentar pensar qué sucede con esas formas de liderazgo local en el marco del proceso en el que surge y se consolida a escala global la lógica estatal.

Por su parte, el artículo de Augusto Gayubas, "Guerra, territorio y cambio social en el valle del Nilo pre estatal", procura evaluar el abordaje teórico de Robert L. Carneiro en su relación con el estudio de la emergencia de sociedades de jefatura en el valle del Nilo, atendiendo a la guerra en su relación tanto con la jerarquización, el territorio, y el problema del cambio social.

Marcos Cabobianco, en "La rebelión primigenia en el antiguo Egipto y en Suazilandia", centra su atención en la caracterización de la ceremonia Ncwala de los swazi como un ritual de rebelión al tiempo que realiza una comparación con los relatos 
míticos del antiguo Egipto. Su búsqueda se orienta a realizar una aproximación al cruce entre una Historia y una Antropología que, en los hechos, discurre por sendas paralelas.

"Las formaciones sociales en las postrimerías de la prehistoria palestinense: el periodo Calcolítico" de Pablo F. Jaruf, pone el foco en el período Calcolítico tardío y las probables formas de liderazgo presentes en el mismo. Su propuesta de trabajo es problematizar el supuesto de que las innovaciones técnicas tienen un efecto directo en la centralización y jerarquización de las formas de liderazgo. En ese sentido, plantea que las innovaciones técnicas son el resultado de determinadas relaciones de producción y que son estas últimas las que, a través de un proceso dialéctico con los demás elementos de lo social, determinan la formación social de un periodo.

"Poderes locales durante el periodo Paleobabilónico" de Andrea Seri, sostiene que el apartarse de visiones que privilegian la centralidad del Estado permite comprender complejidades en la articulación de redes de poder superpuestas que no son aparentes desde una perspectiva eminentemente estatal. Así, pone el foco en un grupo de instituciones con relativa independencia del Estado, a los fines de considerar otras constelaciones de poder que operaban en la sociedad, y en el rol de autoridades locales como el jefe de la ciudad, los ancianos, la ciudad y la asamblea.

Emanuel Pfoh realiza una revisión de la relación de "vasallaje" hitita proporcionada por K. Ebeling, planteando que la idea de un "feudalismo hitita" debe ser con total probabilidad rechazada como posibilidad interpretativa, debido esencialmente al anacronismo que supone y a las características que connota respecto de las relaciones feudo vasalláticas medievales.

La segunda parte, Grecia antigua, comienza con el texto de Mariano J. Requena, "Clases sociales, subjetividad política y tensión democrática. Apuntes para una discusión sobre la determinación clasista en la Atenas clásica". Allí, Requena reflexiona sobre la lucha de clases a partir de la democracia ateniense desde la perspectiva abierta por el materialismo histórico. Para llevar esto a cabo, toma como paradigmática la postura de Ste. Croix, quien se ocupaba tanto del mundo antiguo como de explicitar los conceptos que el marxismo aplicaba a la interpretación histórica.

Diego Paiaro, por su parte, se propone analizar el miedo a la tiranía como emoción o sentimiento colectivo del demos ateniense y su relación con el régimen político durante la democracia; bajo la noción de "miedo a la tiranía" engloba un constructo en el que se entremezclan tanto representaciones simbólicas y estructuras mentales, como así también percepciones, emociones y sentimientos comunitarios que favorecieron el desarrollo de una identidad cívica que, entre sus puntos más salientes, compelía a los ciudadanos a tomar parte activa en la defensa de la democracia.

En "Libros, intelectuales y democracia en la Atenas clásica: el caso de la persecución a Protágoras de Abdera", Sergio Barrionuevo plantea que el vínculo entre escritura y democracia en Atenas clásica es producto de un proceso histórico en el cual el estatuto de la escritura se fue transformando en función de los propios actos de escritura. Discute la forma de circulación de textos y libros durante el periodo clásico y también el vínculo 
entre libros y sector intelectual en Atenas durante el siglo V. Por último, analiza la persecución a los intelectuales deteniéndose en el caso de Protágoras, para lo que argumenta que la persecución a los intelectuales vinculados con la producción de libros es considerada un elemento que desarticula la unidad de la pólis, por su relación con prácticas sectoriales de producción de sentido.

Claudia Fernández, en "Justicia poética y política democrática en la comedia de Aristófanes", plantea que la comedia aristofánica es abiertamente política. Se sumerge en los problemas políticos de Atenas en el momento mismo de la presentación teatral (la Guerra del Peloponeso), refiere también al comportamiento inapropiado de las masas frente a los demagogos de turno, o a la incompetencia de la asamblea y su negativa a tratar temas de verdadera importancia, o a la alteración cívica producida por las cortes democráticas. Sostiene la autora que estos desórdenes de índole política y social son los disparadores de la crítica del héroe cómico, quien provee una solución al problema que es fantástica o utópica, es decir, inviable o ineficaz en la vida real. No parece haber sido la misión intelectual y social del género cómico la de ofrecer una solución práctica para los problemas políticos.

Julián Gallego nos presenta un trabajo titulado "De la democracia a la oligarquía y de la oligarquía a la democracia, una y otra vez", que se enfoca en el periodo extendido entre 411 y 403 a.C., reconociéndolo como uno de los más conflictivos de la historia ateniense. El paso de la democracia a la oligarquía y de la oligarquía a la democracia, una y otra vez, como llama el autor a su obra, presenta una cuestión controvertida que radica en la reflexión acerca de si una ciudad sigue siendo o no la misma en caso de producirse un cambio en la politeía, independientemente de que conserve o no el mismo nombre y que sus habitantes sean o no los mismos que antes del cambio, problema central del libro III de la Política de Aristóteles.

Cerrando esta sección, Claudia Mársico, analiza el caso del Hierón de Jenofonte para analizar las tiranías griegas entre los socráticos. El tratamiento de las tiranías en esta obra permite examinar las claves de análisis de dicho modelo político, esbozar razones respecto de la elección de los protagonistas en este género discursivo (diálogo socrático), y establecer los motivos que configuran la relación propuesta entre cultores del saber y ejercicio del poder. Además, a través de esto plantea la posibilidad de acercamiento a la pervivencia contemporánea del problema, cifrada en la presencia del Hierón como base para la polémica que sobre esta cuestión sostuvieron Strauss y Kojeve.

Inaugurando la tercera y última parte del libro, mundo romano y antigüedad tardía, Carlos García Mac Gaw trae el debate en torno a la interpretación del modo de producción antiguo como preclasista en su artículo "La política y la Ciudad-Estado. Reflexiones sobre el modo de producción antiguo". Busca avanzar en una formulación teórica acorde con el desarrollo de los estudios del mundo mediterráneo clásico, y con el impulso que la arqueología ha aportado a la cuestión.

Fernando Piantanida, en "Guerras serviles y Estados rebeldes: las monarquías de Euno y Salvio", aborda a partir de la principal fuente escrita (los fragmentos de los 
últimos libros de Diodoro Sículo), el análisis de las prácticas de organización política que los esclavos rebeldes emplearon para llevar a cabo sus revueltas y las instituciones creadas y, además, a través de un análisis de la información numismática, trata el problema de la composición social del Estado rebelde gobernado por el rey Euno.

En “El problema de la participación política popular en la República romana tardía. Lógicas de articulación del conflicto social", Juan Manuel Gerardi, tomando como punto de partida las interpretaciones heterogéneas sobre la caracterización del régimen político romano, intenta evaluar los aportes del debate en curso, a la luz de los cambios historiográficos desde la segunda mitad del siglo XX y, a la vez, aportar nuevos elementos para comprender la asociación política de la plebe en la crisis de la república romana, para de esta manera no circunscribirse a la glosa de los antecedentes.

Alicia Schniebs, en "Lugares, poder y representación en las Metamorfosis de Ovidio", propone algunas reflexiones acerca de la construcción de los lugares de poder en esta obra y de su posible vínculo entre ella y la redefinición del espacio acarreada por la instalación y consolidación del régimen autocrático en términos de la producción y circulación de los discursos que las representaciones republicanas conciben como sostén del entramado político y social. Pone su foco de atención en la asamblea de los dioses del libro I y en su diálogo con otros pasajes de la obra.

“El imperio como instrumento divino. Cipriano de Cartago y su perspectiva sobre Roma" de Mariano Spléndido, analiza cómo Cipriano, obispo de Cartago entre 248 y 258, concibió la idea de Roma y su rol en medio de las vicisitudes que atravesaban los cristianos durante el periodo de las persecuciones de Decio y Valeriano. Para comprender mejor las posturas de Cipriano, quien supo hacer uso de las tradiciones cristianas locales para reorganizar la cosmovisión de una comunidad quebrada por la apostasía masiva, el autor las confronta con las halladas en otros autores contemporáneos, como Dionisio de Alejandría, o procedentes del área, como Tertuliano y Minucio Félix.

Rodolfo Lamboglia, en "Zenobia de Palmira, entre la conquista militar y la captatio benevolentiae", refiere a la singular construcción de poder llevada adelante por parte de Zenobia de Palmira, en el trascurso de algunos pocos años durante la segunda mitad del siglo III. Un particular intento de llevar adelante un proceso de organización políticomilitar que desafió al poder romano en un territorio que constituía una de las regiones con uno de los entramados más complejos y dinámicos de tradiciones étnicas locales, diversidad religiosa e influencias culturales foráneas. Reflexiona este asunto en torno a los trabajos de Fergus Millar y Antonio Baldini, y las razones teóricas que condujeron a estos investigadores a conclusiones opuestas.

"Los curiales en la Galia meridional tardoantigua y la cuestión fiscal" de Pablo Sarachu propone una posible solución al debate historiográfico en torno a si los curiales en la Galia de la antigüedad tardía fueron beneficiados o perjudicados por el papel que se les asignó en el sistema tributario reformado por Diocleciano. 


\section{1 | Reseña}

Cerrando la última sección y el libro, tenemos "Discursos sobre la sociedad y el Imperio en Bizancio en el siglo X" de Pablo Ubierna, que sienta las bases de una discusión futura de cómo, a principios del siglo X, confluían una serie de discursos sobre la sociedad y el imperio: el jurídico, el exegético, el profético y el filosófico, que debían o bien convivir o bien anularse.

Regímenes políticos en el Mediterráneo antiguo logra ser una recopilación heterogénea de trabajos sobre el tema, que ofrece distintos enfoques, perspectivas y problemáticas dentro del tópico general. Nos encontramos con múltiples aproximaciones, algunos textos profundizan en debates ya instalados, otros buscan aportar algún elemento nuevo a esos debates. Algunos autores focalizan sobre la evidencia (arqueológica, literaria, etc.) sin profundizar en conclusiones novedosas, mientras que también se observan algunos escritos que buscan alejarse de las conclusiones de antaño para acercarse a la temática desde una perspectiva totalmente nueva.

A pesar de los distintos ángulos desde los que son tratados los regímenes políticos, esta obra es útil para aquellos especialistas en la cuestión política en la antigüedad. En las 286 páginas que contiene el libro, los lectores encontrarán distintos abordajes teóricometodológicos, que les permitirán complementar trabajos previos sobre el tema.

Leandro Nahuel Fernández Roveda

Universidad Nacional de Córdoba

lnfr1707@hotmail.com 